\title{
Evaluation of Methylobacterium radiotolerance and Sphyngomonas yanoikoaie in Sentinel Lymph Nodes of Breast Cancer Cases
}

\author{
Hamid Reza Yazdi', Abolfazl Movafagh ${ }^{2 *}$, Fateme Fallah ${ }^{3}$, Shohreh Alizadeh \\ Shargh $^{2}$, Neda Mansouri ${ }^{2}$, Atefeh Heidary Pour ${ }^{4}$, Mehrdad Hashemi ${ }^{5}$
}

\begin{abstract}
It has been established that different kinds of bacteria agents are involved in various cancers. Although the mechanism of tumorigenesis is not clearly understood, there is evidence for the presence of bacteria within tumors, with at least a progression effect for some bacteria that prepare suitable microenvironments for tumor cell growth. The aim of current study was to evaluate bacterial dysbiosis in sentinel lymph nodes of breast cancer patients. One hundred and twenty three fresh-frozen sentinel lymph nodes and a corresponding number of normal adjacent breast tissue specimens and five normal mastectomy samples were investigated employing RT-PCR. In addition using genus-specific primers were applied. There was a significant differences as presence of Methylobacterium radiotolerance DNA recorded between patients and normal control group $(\mathrm{p}=0.0)$. Based on our research work, further studies into the role of microbes in breast cancer would be of great interest.
\end{abstract}

Keywords: Breast cancer - sentinel lymph nodes - Methylobacterium radiotolerance - Sphyngomonas yanoikoaie

Asian Pac J Cancer Prev, 17, Cancer Control in Western Asia Special Issue, 279-285

\section{Introduction}

The association between the development of cancer and bacterial agents, has been proved in recent years (Mager, 2006). Some evidence shows that relation between helicobacter pylori infection and gastric cancer and some other type of malignancies such as lymphoma were reported (Cover and Blaser, 2009; Polk and Peek, 2010). Other types of bacteria has been shown that present their infection in tumor tissues (Toso et al., 2002; Heppner et al., 1978). Indeed, some bacteria replicate and establish specifically within tumor cells (Baban et al., 2010).

Infection with microbial agents is linked to higher risk of malignancy with significant attribution of bacterial infections (Pujol and Devesa, 2005; Ord and Blanchaert, 2001). Some species of bacteria, like salmonella typhi is in association with gall bladder cancer (Vaishnavi et al., 2005), streptococcus bovis and colon cancer (Littman et al., 2004), and chlamydia pneumonia reported with lung cancer (Kuper et al., 2000).

Bacteria can change the immune system status and suppress it's effective response and even evade to immune system (Kuper et al., 2000). By long-term infection with bacteria as chronic disease, also bacteria can produce some dangerous agents such as toxins that able to change cell cycle regulation and as the consequence, alter cell growth (Koyi et al., 2001).

The anaerobic bacteria (Peptostreptococcus) detected in the lymph nodes have been detected in gastrointestinal tumor tissue, suggesting that the oral mucosal defect can induce translocation of anaerobes into the neighbor lymphatic nodes (Sakamoto et al., 1999). In another study, some of microbial biomarkers that present in the salivary, are specific for pancreatic cancer (Sjostedt et al., 1988).

In recent study, Xuan and his co-workers, investigated Methylobacterium radiotolerance and Sphyngomonas yanoikuyae in the breast cancer tissue with adjacent normal tissue. They found relative abundances of these two bacterial species were inversely correlated in paired normal breast tissue but not in tumor tissue, showing the dysbiosis is associated with breast cancer (Caiyun et al., 2014).

${ }^{1}$ Department of Microbiology, Pishva Islamic Azad Uinversity ${ }^{2}$ Department of Medical Genetics, ${ }^{3}$ Department of Microbiology, School of Medicine, Shahid Beheshti University of Medical Sciences, ${ }^{4}$ Department of Cell and Molecular Biology, Pharmaceutical Sciences Branch, ${ }^{5}$ Department of Genetic, Islamic Azad University, Tehran Medical Sciences Branch, Tehran, Iran. *For correspondence: movafagh.a@sbmu.ac.ir 


\section{Material and Methods}

Ethics statement for obtaining breast tissue specimens

One hundred twenty three fresh-frozen sentinel lymph node of breast cancer, and 123 normal adjacent breast tissue and 5 normal mastectomy samples were obtained in accordance with institutional requirements according to health ministry guidelines. The study protocol was approved by the Ethical Committee of the Pishva Islamic Azad Uinversity. Written consent was specifically waived by the approving of pathological consents. Extracted bacteria DNA from Methylo bacterium Radiotolerance and Sphyngomonas Yanoikuae was obtained from microbiology department of Radboud University, Nichmegen, Netherland.

Genomic DNA ( $g D N A)$ extraction from fresh-frozen tissue Total genomic DNA was extracted from FFPE breast tissues using Sigma,GenElute ${ }^{\mathrm{TM}}$ Mammalian Genomic DNAMiniprep KitProtocol(G1N10) per manufacturer's instructions with slight modifications. Purified gDNA was eluted twice from the column using ultrapure water. All extractions were performed in a designated clean (pre-PCR) room.RT- PCR, Sybr green for bacterial copy numbersRT-PCR was performed using the genus-specific primers $5 \mathrm{~F}$ (forward, 5' - AACGTGCCTTCTGGTCTGG -3') and 8R (reverse, 5'- TCCGGCAGTAAACCTTTCCC-3') were used to quantify M. radiotolerans(AY616142.1 (71.153), amplicon size 83bp) and, Sph-spt 694F (forward, 5'- AAGGCGACGATCCTTAGCTG-3') (AF331661.1(2264493... 2264177, 317 bp) and Sph-spt 983R (reverse, 5'- CGGGCTTTCACCTCTGACTT-3') were used to quantify Sphingomonason microbial
DNA extracted from fresh frozen tissue. Primers designed were using "Primer blast 3, NCBI" software. The reaction condition was as follows: Sybr buffer $10 \mu \mathrm{l}$, Primer F $(10 \mathrm{pmol} / \mu \mathrm{l}) 0.5(10 \mathrm{pmol} / \mu \mathrm{l})$, Primer R $(10 \mathrm{pmol} / \mu \mathrm{l}) 0.5$ Primer R(10pmol/ $\mu \mathrm{l})$, ddH2O $\mu \mathrm{l}$, DNA $2 \mu \mathrm{l}$, final volume $20 \mu \mathrm{l}$. The cycling program for Methylobacterium Radiotolerance was Pre

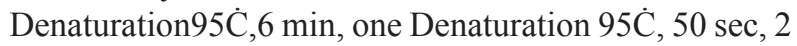

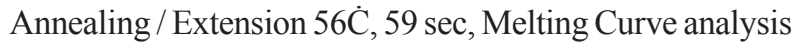
70-95, 0.5S/degree and for Sphyngomonas Yanoikoae was; Pre Denaturation95,5 min, 1Denaturation 95Cं, $60 \mathrm{sec}, 2$ Annealing/ Exiension 54, $60 \mathrm{sec}$, Melting Curve analysis 70-95, 0.5S/degree (Figure1).

All samples from pyrosequencing were also assessed for bacterial sequence confirmation (Subjects 1-5, the positive RT-PCR products for Methylo bacterium Radiotolerance, and 4 positive samples for Shpyngomonas Yanoikoae) (Figure 2). DNA from healthy specimens was obtained from patients undergoing reduction mammoplasty, with no evidence of breast cancer. Bacterial copy numbers were normalised by the total amount $(\mu \mathrm{g})$ of extracted DNA of beta-actin house keeping gene. Samples were randomized and processed in a blinded manner.

\section{Statistical analysis}

All data were analyzed with Statistical Product and Service Solutions (SPSS) software (version 17.0, SPSS Inc., Chicago, IL, USA). Participants were categorized into three groups: Breast cancer, normal adjacent breast tissue and normal mastectomy samples were obtained.

Comparisons in stages among three groups were performed using the Chi square test and comparisons between each two groups were performed using the partition of Chi square test. Differences were considered
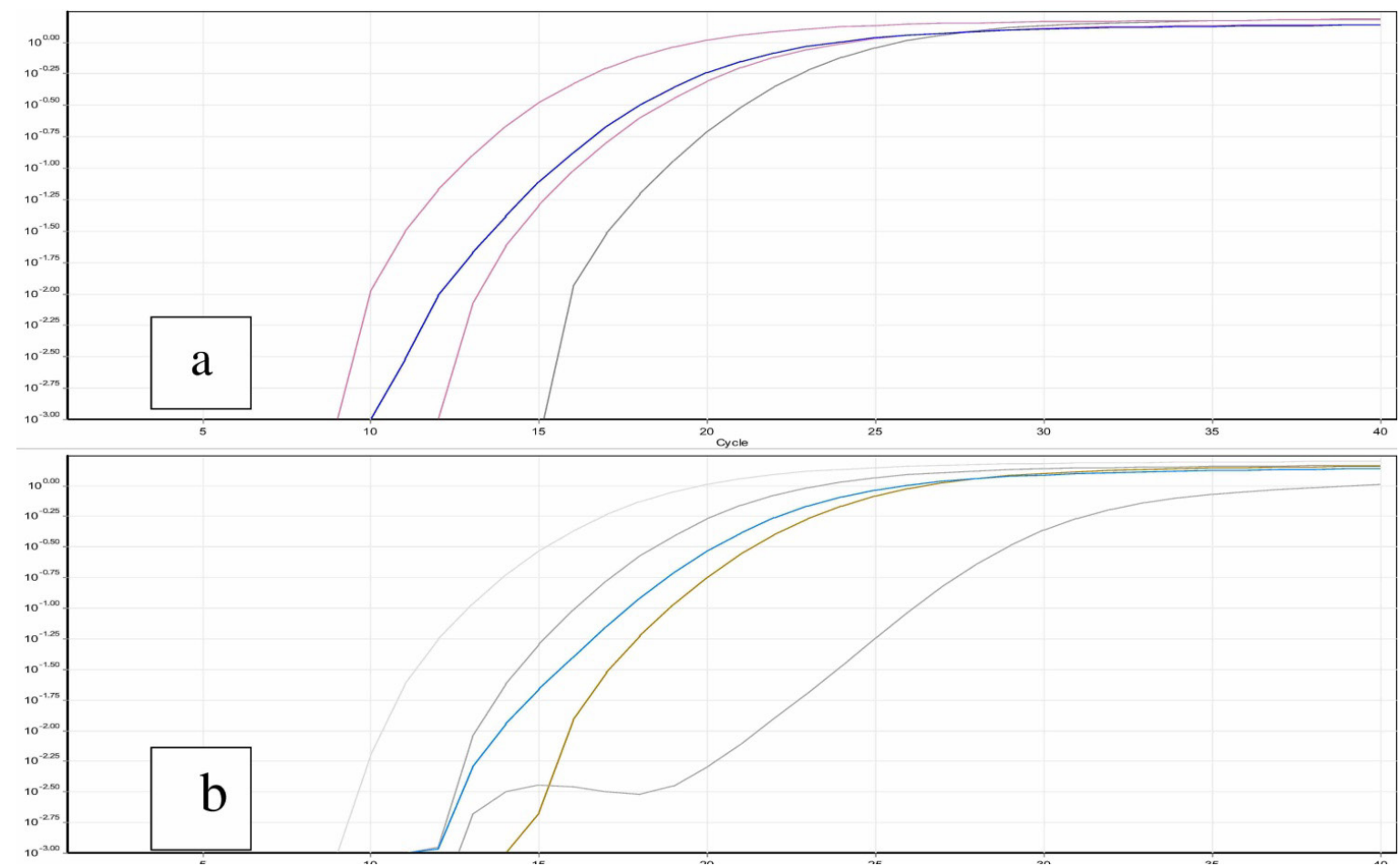

Figure 1. The Sybr Green RT-PCR Graphs for Methylobacteriumradiotolerans and Sphyngomonas Yanoikoae, DNA Sample, Figure1a: Methylobacterium Radiotolerance Figure1b: Sphyngomonas Yanoikoae. 
File: 88-9-16S_5413P-5F.abl Run Ended: Dec 72009 20:20:45 Signal G:407 A:237 T:189 C:165 Comment:

Sample: $5413 \mathrm{P}-1 \mathrm{~F} \quad$ Lane: 10 Base spacing $14.06 \quad 826$ base in 10110 scans
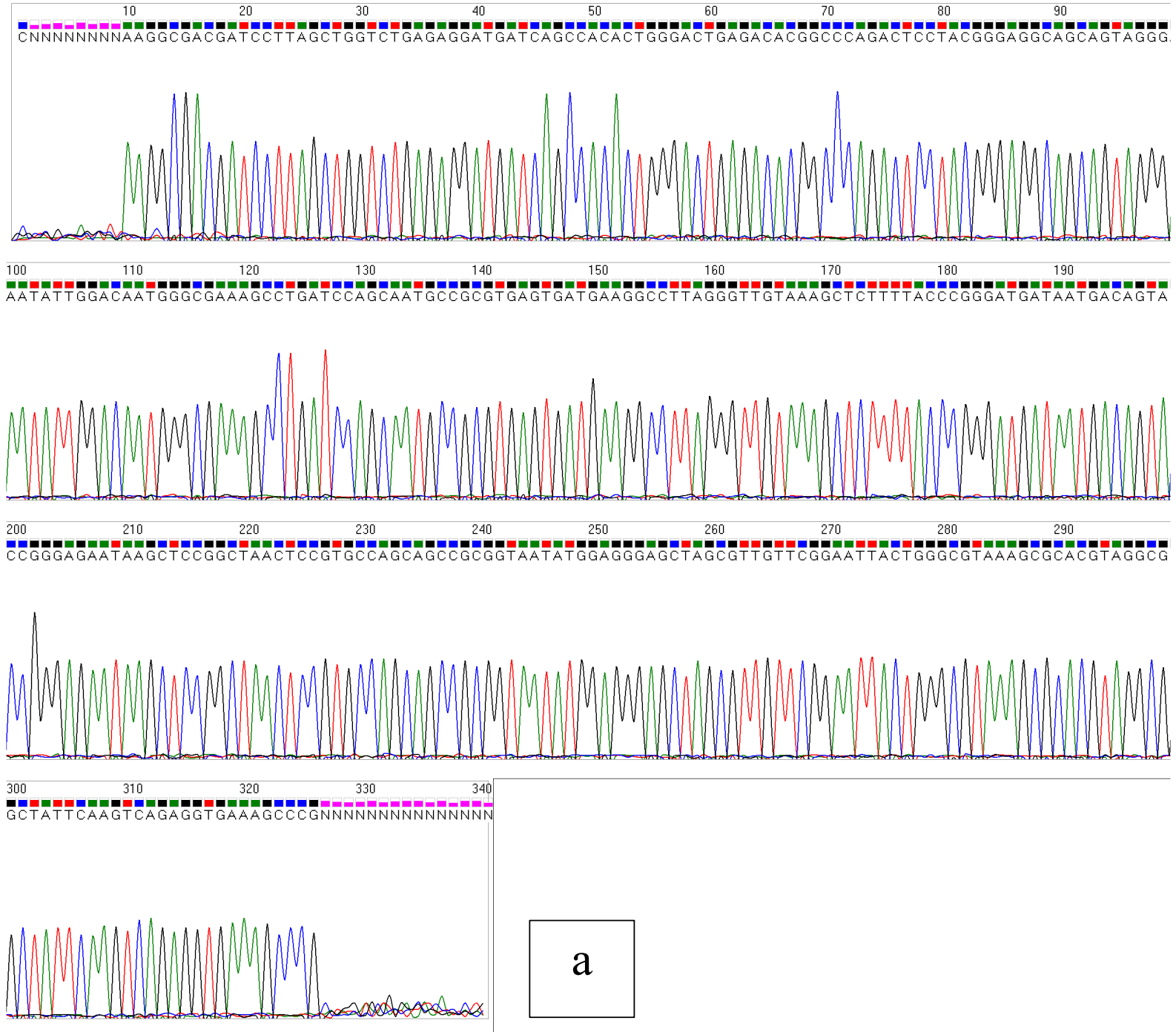

File: 88-9-16S_5413P-1E.ab1 Run Ended: Dec 72009 20:20:45 Signal G:407 A:237 T:189 C:165 Comment:

Sample: $5413 \mathrm{P}-1 \mathrm{~F} \quad$ Lane: 10 Base spacing $14.06 \quad 826$ base in 10110 scans
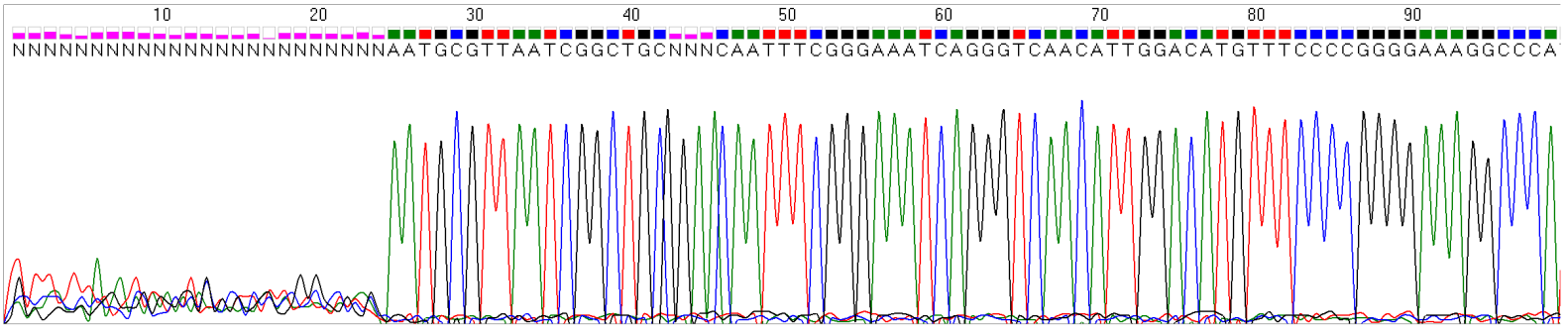

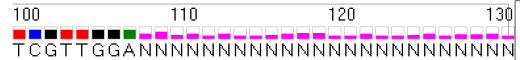

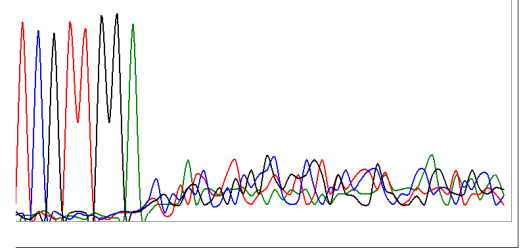

b

Figure 2. A Histogram Example from Pyrosequancing of DNA RT-PCR Products for Methylobacterium radiotolerance (a) and Sphyngomonas yanoikoae (b) 

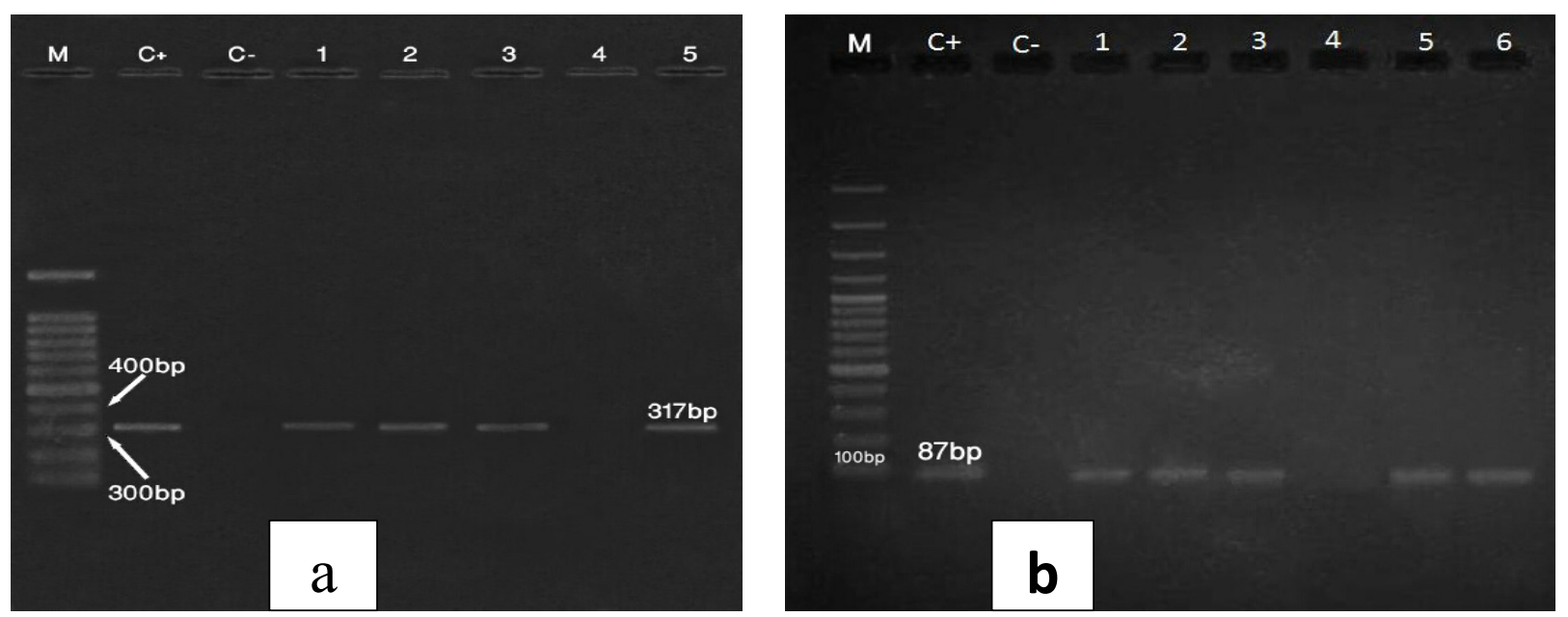

Figure 3. Electrophoresis of RT-PCR Products in 2\% Agarose Gel, Ladder for Sphyngomonas yanoikoae is 100bp (a) and for Methylobacterium radiotolerance is 50bp (b),c1: Positive Bacterial DNA Control, c2: Normal Mastectomy Breast Tissue,no 2,2,3 Positive Samples from Sentinel Lymph Nodes, No4: Normal Breast Tissue, No 5,6: Positive Sentinel Lymph Node.

as statistically significant if the $\mathrm{P}$ value was $<0.05$.

\section{Result}

In the present study, 123 sentinel lymph node that were pathologically negative, and 123 normal adjacent breast tissue has evaluated. DNA from Methylobacterium Raidiotolerance and Sphyngomonas Yanoikoea as positive control was analyzed. From 123 sample (one of them is excluded because of low quality), 5 sentinel lymph nodes has 5 sample showed Methylo bacterium Radiotolerance DNA and from 123 normal adjacent breast tissue, 4 sample showed Sphyngomonas Yanoikoae DNA (Figure 3).

Evaluation of RT-PCR results with specific primers for Methylo bacterium Radiotolerance

In statistical analysis between cancer and normal samples, there was a significant difference as presence of Methylo bacterium Radiotolerance DNA in tumor samples $(p=0.0)$.

In this survey, 3\% (100 sample) of cancer samples were in stage 1, had not the bacterial content and non of positive samples were in stage 1 . Also of positive $2.1 \%$ (2 samples) and $97.9 \% 993$ negative samples were in stage 2. From $12.5 \%$ (3 sample) of positive samples and $95.5 \%$ (117 sample) of negative samples were stage 3. In Pearson chi-square test, there was a significant relation between stage and DNA of Methylobacterium Radiotolerance,

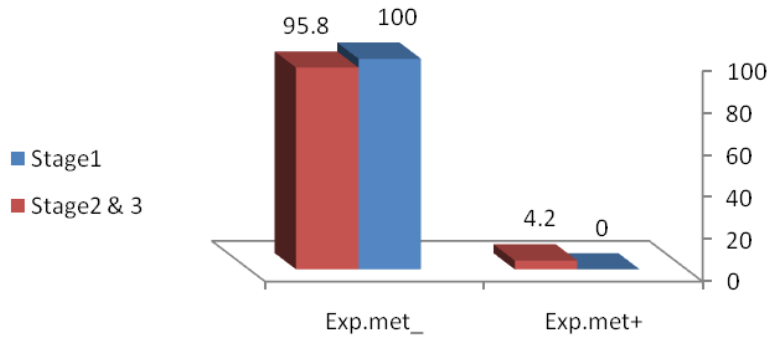

Figure 4. Relation between DNA of Methylobacterium Radiotolerance in Sentinel Lymph Node Samples of Breast Cancer and Stage of Tumor means that in higher stages, the positive results were significantly higher that lower stages of breast cancer $(\mathrm{p}<0.01)$ (Figure 4).

The correlation between DNA of methylobacteriumradiotolerance with breast tumor grade

In $6.4 \%$ (3 samples) of positive samples and $93.6 \%$ (44 sample) of negative samples, were in grade 1 and from $2.7 \%$ ( 2 sample) positive samples and $97.3 \%$ (73 sample)

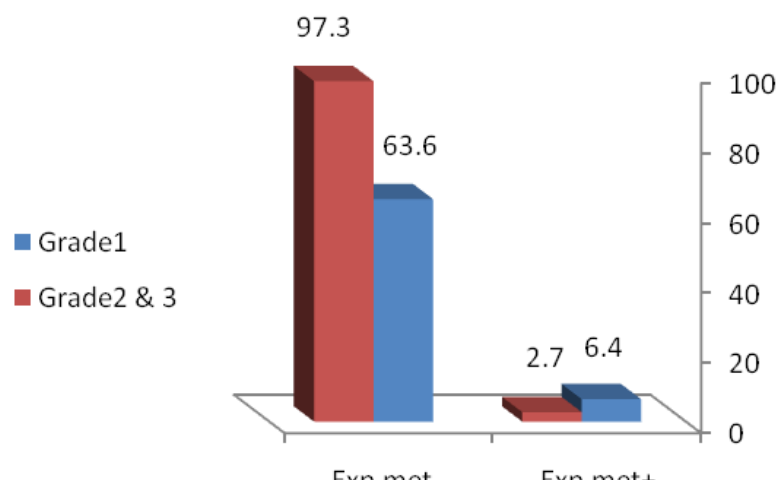

Figure 5. Relation between DNA of Methylobacterium Radiotolerance in Sentinel Lymph Node Samples of Breast Cancer and Grade of Tumor

97.3

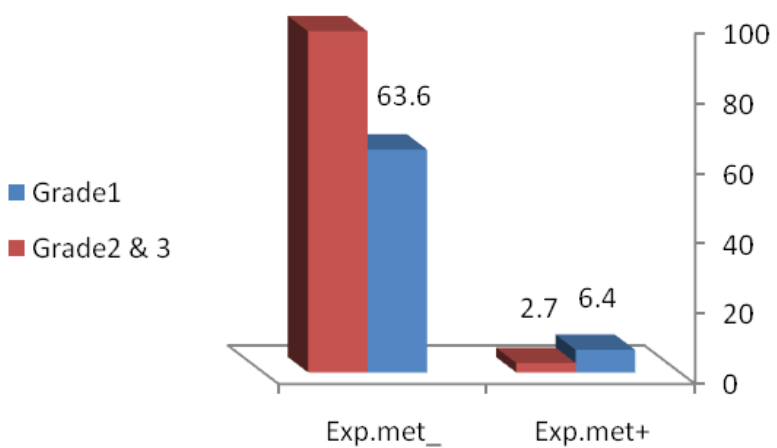

Figure 6. Relation between DNA of Sphyngomonas Yanoikoae in Sentinel Lymph Node Samples of Breast Cancer and Stage of Tumor 


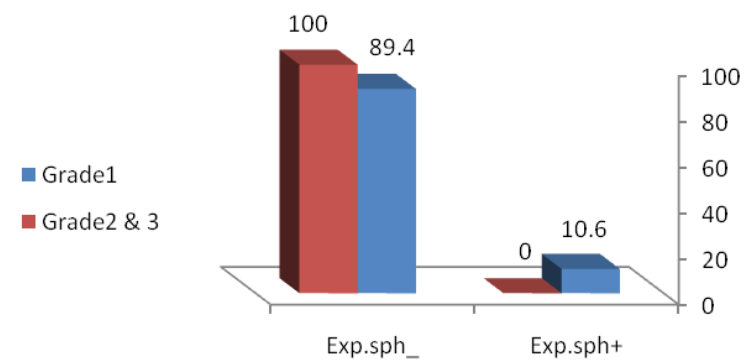

Figure 7: Relation between DNA of

Sphyngomonasyanoikoae in Sentinel Lymph Node Samples of Breast Cancer and Grade of Tumor.

negative samples were in grade 2. In Pearson chi-square test, there was not significant difference between presence of Methylo bacterium Radiotolerance DNA and grade of tumor $(\mathrm{p}=0.37)$ (Figure 5).

Evaluation of RT-PCR results with specific primers for Sphyngomonas Yanoikoae

In statistical analysis between cancer and normal samples, there was a significant difference as presence of Methylo bacterium Radiotolerance DNA in tumor samples $(\mathrm{p}=0.0)$.

The correlation between DNA of Sphyngomonas Yanoikoae with breast tumor stage.

In this study, $33.3 \%$ ( 1 sample) of positive cancer samples and $66.7 \%$ (2 sample) with negative result, were in stage 1 . Also of positive $4.2 \%$ (4 samples) and $95.8 \%$ (114 sample) negative samples were in stage 2 and 3 . In Pearson chi-square test, there wasnot a significant relation between stage and DNA ofSphyngomonas Yanoikoae ( $\mathrm{p}=$ 1.000) (Figure 6).

The correlation between DNA of sphyngomonasyanoikoae with breast tumor grade

In this study, $6.4 \%$ (3 sample) of positive cancer samples and $93.6 \%$ ( 44 sample) with negative result, were in grade 1. Also of positive 2.7\% (2 samples) and 97.3\% (73 sample) negative samples were in grade 2 and 3 . In Pearson chi-square test, there was not a significant relation between stage and DNA of Sphyngomonas Yanoikoae ( $\mathrm{p}=$ 0.372) (Figure 7).

In assessment for locality of patients (urban-rural) or metastasis occurrence after 3 moths of sampling, there were no evidence for relationship between Methylo bacterium Radiotolerance and Sphyngomonas Yanoikoae content with them $(p=1.0)$ (data not shown).

\section{Discussion}

The bacterial involvement in various kinds of cancer is established in several studies (Mager, 2006). Screening researches for presence of bacteria in cancer tissues in histologically different kinds of tissue, can reveal new aspects for this relation. Some bacteria can adapt with tumor microenvironment, serves the area for finding the exact mechanism and bacterial potential in tumorigenesis.

In the current study, the results revealed that the significant difference for presence of sphyngomonasyanoikoae in normal tissue and also, presence of methyl bacterium radiotolerance in cancer tissue $(\mathrm{p}=0.0)$.
Moreover, in this study, the correlation between tumor's pathologic merkers such stage, grade, current metastasis and locality of patients for living region all positive samples is evaluated, and it revealed that methyl bacterium radiotolerancenin breast cancer is more prevalent in higher stages $(p<0.01)$ but not in correlation with tumor's grade $(p=0.37)$. This insignificant value maybe due to some sentinel lymph nodes had no grade as pathological report and discarded further from analytical tests. Also, in evaluation of presence of shpyngomonasyanoikoae, with tumor's characteristics, there were not the significant correlation between the presence of this bacteria with tumor's stage and grade that the reason of this, maybe due to absence of this bacteria in tumor samples $(p=0.1$ $\mathrm{p}=0.37$ respectively).

The results of statistical analysis for presence of methylobacterium and sphyngomonas with locality and current metastasis, was not significant $(p=1.0)$ that the reason of such finding maybe the result of limited sample number that is usual for sentinel lymph node sample.

In previous studies, it has been shown that the strongest relation between bacterial infection and tumorigenesis, is for helicobacter pylori (Samaras et al., 2010). The second importance is for salmonella typhi, causative agent of thyphoid and can transport the bacteria chronically to bile ducts.

Recently in epidemiologic studies, it has been proved that the carriers of Salmonella Typhi, have the risk for gall bladder carcinoma 8.47 time and 6 times for hepato-billary carcinoma greater than patients that had acute disease and cleared completely from bacteria (Wroblewski et al., 2010).

Moreover, recent studies has revealed that diseases like cancer need to genetical susceptibility that along with primary and secondary progression factors, can promote environmental malignancy (Heidari et al., 2014).

According to several studies, long term infection with Chlamydophila pneumonia, can increase the risk for lung cancer (Caygill et al., 1994).

The mechanism underlying the changes in tumor cells for bacteria that cause the localization of bacteria in tumor tissues recorded in the literature (Lazcano-Ponce et al., 2001).

Also in evaluation of oral squamous cell carcinoma (OSCC), the DNA content of saliva in healthy persons and patients for capnocytophagagingin valis, prevotellamelaninogenica, streptococcus mitis infection, it was meaningful difference between two groups $(\mathrm{p}<$ 0.01 ), in that, $80 \%$ of positive subjects went to cancerous event (sensitivity) whereas in $83 \%$ of control group (specificity), non of these bacteria were not observed in that, the sensitivity and specificity in parallel groups were $80 \%$ and $82 \%$ and now it has been well known as good predictor for OSCC (Anttila et al., 2003).

In case-control study by Littman and co-wokers, on 508 double sample with anti IgA antibody titer, higher than 16 , were cut pointed as positive and this criteria was associated with 1.2 time greater risk for lung cancer (Littman et al., 2004).

It is well known that the change in cell surface carbohydrates is one of the malignant transformation 
and the cancer is the molecular disease, that shows the changes in glycoconjugates in cell surface (Hakomori 1996). In the study of Xuan and colleagues for microbial dysbiosis in breast cancer, two species, methyl bacterium radiotolerance and shpyngomonasyanoikoae is evaluated as causative agents. They detected DNA of these two bacteria on paraffin embedded and fresh frozen breast tissues.

From different kinds of bacteria, they found the meaningful difference for these two bacteria in normal breast tissue and cancerous breast tissues $(p<0.01, p=0.01$ respectively). In comparison in normal and cancer tissues, the sphyngomonasyanoikoae, showed the significant difference in normal tissues $(p=0.04)$ and in the same time, the presence the methyl bacterium radiotolerance, was much more higher in cancer tissues $(p=0.25)$ than other bacteria types, but not higher enough that makes it significant comparing to normal tissues.

In Xuan's study, it is shown that the presence is about $40 \%$ of sphyngomonasyanoikoae in normal tissue. Also, there was the reverse significant correlation between presence of methyl bacterium radiotolerance and sphyngomonasyanoikoae in normal tissues $(p=0.0)$, but not significant in tumor tissues Xuan (Xuan et al., 2014; Shargh et al., 2014). Taken together, these data indicate that microbial DNA involvement is present in the breast tissues and that bacteria adapt with tumor microenvironment, serves the area for finding the exact mechanism and bacterial potential in tumorigenesis. The link between dysbiosis and breast cancer which has potential diagnostic and therapeutic implications must be considered. According to our research work, warrants further study into the role of microbes in breast cancer and would be of great interest.

\section{Acknowledgments}

We thank NiloofarSafavifor technical assistance and Dr. Hemad Yasaie (Brunel University UK) and DrAzim NejatZadeh for helpful discussions. Also this research work is part of thesis work of Hamidreza Yazdi.This work was supported by Pishva Islamic Azad Uinversity, Tehran Iran. There are no conflicts of interest.

\section{References}

Anttila T, Koskela P, Leinonen M, et al (2003). Chlamydia pneumoniae infection and the risk of female early-onset lung cancer. Int $J$ Cancer, 107, 681-2.

Baban CK, Cronin M, O'Hanlon D, et al (2010). Bacteria as vectors for gene therapy of cancer. Bioeng Bugs, 1, 385-94.

Caygill CP, Hill MJ, Braddick M, et al (1994). Cancer mortality inchronic typhoid and paratyphoid carriers. Lancet, 343, 83-4.

Caiyun X, Shamonki JM, Chung A, et al (2014). Microbial dysbiosis is associated with human breast cancer. PLoS ONE, 9, 83744.

Cover TL, Blaser MJ (2009). Helicobacter pylori in health and disease. Gastroenterology, 136, 1863-73.

Fardmanesh H, Shekari M, Movafagh A, et al (2016). Upregulation of the double-stranded RNA binding protein DGCR8 in invasive ductal breast carcinoma. Gene, $\mathbf{5 8 ,}$
146-51.

Heppner F, Mose JR (1978). The liquefaction (Oncolysis) of malignant gliomas by anon pathogenic Clostridium. Acta Neurochir (Wien), 42, 123-5.

Heidari MH, Porghasem M, Mirzaei N, et al (2014). The effect of high level natural ionizing radiation on expression of PSA, CA19-9 and CEA tumor markers in blood serum of inhabitants of Ramsar, Iran. J Environ Radioact, 128, 64-7.

Biarc J, Nguyen IS, Pini A, et al (2004). Carcinogenicproperties of proteins with pro-inflammatory activity from Streptococcus infantarius (formerly S. bovis). Carcinogenesis, 25, 1477-84.

Hakomori S (1996). Tumor malignancy defined by aberrant glycosylationand sphingo (glyco)lipid metabolism. Cancer Res, 56, 5309-18.

Koyi H, Branden E, Gnarpe J, et al (2001). An association between chronic infection with Chlamydia pneumoniae and lung cancer. A prospective 2-year study. APMIS, 109, 572-80.

Kuper H, Adami HO, Trichopoulos D (2000). Infections as a major preventable cause of human cancer. J Intern Med, 248, 171-83.

Lazcano-Ponce EC, Miquel JF, Munoz N, et al (2001). Epidemiology and molecular pathology of gallbladder cancer. CA Cancer J Clin, 51, 349-64.

Littman AJ, White E, Jackson LA, et al (2004). Chlamydia pneumoniae infection and risk of lung cancer. Cancer Epidemiol Biomarkers Prev, 13, 1624-30.

Littman AJ, Thornquist MD, White E, et al (2004). Prior lung disease and risk of lung cancer in a large prospective study. Cancer Causes Control, 15, 819-27.

Mager DL (2006). Bacteria and cancer: cause, coincidence or cure? Arev Jour Trans Med, 28, 14-25.

Movafagh A, Hajifathali A, Isfahani F, et al (2012). Geographic heterogeneity of cytogenetic characteristics of acute myeloid leukemia in the early detection. Iran J Cancer Prev, 2, 85-9.

Movafagh A, Mirfakhraei R, Mousavi-Jarrahi A(2011). Frequent incidence of double minute chromosomes in cancers, with special up-to-date reference to leukemia. Asian Pac J Cancer Prev, 12, 3453-6.

Movafagh A, Hajifathali A, Zamani M (2011). Secondary chromosomal abnormalities of de novo acute myeloid leukemia-a first report from the Middle East. Asian Pac J Cancer Prev, 12, 2991-4.

Ord RA, Blanchaert RH (2001). Current management of oral cancer. A multidisciplinary approach. J Am Dent Assoc, 132, 19-23.

Polk DB, Peek RM (2010). Helicobacter pylori gastric cancer and beyond. Nat Rev Cancer, 10, 403-14.

Pujol FH, Devesa M (2005). Genotypic variability of hepatitis viruses associated with chronic infection and the development of hepatocellular carcinoma. J Clin Gastroenterol, 39, 611-8.

Sakamoto H, Sasaki J, Nord CE (1999). Isolation of bacteria from cervical lymph nodes inpatients with oral cancer. Arch Oral Biol, 44, 789-93.

Samaras V, Rafailidis PI, Mourtzoukou EG, et al (2010). Chronic bacterial and parasitic infections and cancer: a review. $J$ Infect Dev Ctries, 4, 267-81.

Seifi-Alan M, Shamsi R, Ghafouri-Fard S, et al (2014). Expression analysis of two cancer-testis genes, FBXO39 and TDRD4, in breast cancer tissues and cell lines. Asian Pac J Cancer Prev, 14, 6625-9.

Sjostedt S, Kager L, Heimdahl A, et al (1988). Microbial colonization of tumors in relation to the uppergastrointestinal tract in patients with gastric carcinoma. Ann Surg, 207, 341-6.

Shargh SA, Sakizli M, Khalaj V, et al (2014). Downregulation 
of E-cadherin expression in breast cancer by promoter hypermethylation and itsrelation with progression and prognosis of tumor. Med Oncol, 31, 250.

Toso JF, Gill VJ, Hwu P, et al (2002). Phase I study of the intravenous administration ofattenuated Salmonella typhimurium to patients with metastaticmelanoma. J Clin Oncol, 20, 142-52.

Vaishnavi C, Kochhar R, Singh G, et al (2005). Epidemiology of typhoid carriers among blood donors and patients with biliary, gastrointestinal and other related diseases. Microbiol Immunol, 49, 107-12.

Wroblewski LE, Peek RM, Wilson KT (2010). Helicobacter pylori and Gastric Cancer: Factors That Modulate Disease Risk. doi: 10.1128/CMR.00011-10. Clin Microbiol Rev, 23, 713-39.

Xuan C, Shamonki JM, Chung A, et al (2014). Microbial dysbiosis is associated with human breast cancer. PLoS One, 9, 83744. 